\title{
Mechanical Loading Model of Main Bearing of Wind Turbine Based on Test Bench
}

\author{
Xing Yang ${ }^{1, ~ *, ~ T a o ~ Z h a n g ~}{ }^{1}$, Lei Li ${ }^{2,3}$, Ya-qian Wang ${ }^{3}$ \\ ${ }^{1}$ School of Mechanical Electronic and Information Engineering, China University of Mining and Technology (Beijing), Beijing, China \\ ${ }^{2}$ School of Mechanical and Materials Engineering, North China University of Technology, Beijing, China \\ ${ }^{3}$ School of Mechanical and Electrical Engineering, Beijing Polytechnic College, Beijing, China \\ Email address: \\ cumtb_yx@126.com (Xing Yang), cumtb_zt@163.com (Tao Zhang), li18801302123@126.com (Lei Li), \\ ya2603403697@163.com (Ya-qian Wang) \\ ${ }^{*}$ Corresponding author
}

\section{To cite this article:}

Xing Yang, Tao Zhang, Lei Li, Ya-qian Wang. Mechanical Loading Model of Main Bearing of Wind Turbine Based on Test Bench. Engineering and Applied Sciences. Vol. 6, No. 3, 2021, pp. 55-65. doi: 10.11648/j.eas.20210603.13

Received: June 21, 2021; Accepted: July 1, 2021; Published: July 7, 2021

\begin{abstract}
Wind-turbine main bearing has to withstand dynamic loads with different directions and different magnitudes in complex environments, and its stable operation has a vital impact on the performance of the entire wind turbine. Therefore, the fatigue strength test of wind turbine bearing is helpful to ensure the normal operation of the whole wind turbine. According to the actual force of main bearing in natural environment, this paper designed a large-scale wind-turbine bearing test bench to detect the deformation performance of the bearing. Through the establishment of the mechanical loading model, the simulation of the actual working conditions of main bearing is realized by the loading of the eight hydraulic cylinders of the test bench, and the radial and axial displacement of the test bearing under different wind conditions are recorded by displacement sensors. A number of temperature sensors are used to monitor the real-time temperature change of the bearing inner ring. The test results show that the loading effect of eight hydraulic cylinders can realize the force of wind turbine bearing under wind load, and the test bench can effectively detect wind-turbine bearings with a diameter of $2.5 \mathrm{~m}$. The mechanical loading method and test results can provide guidance for further inspection of the wind-turbine bearing.
\end{abstract}

Keywords: Wind Turbine, Main Bearing, Force System Transformation, Bearing Test Bench, Hydraulic Cylinder

\section{Introduction}

Wind energy is a sustainable and renewable energy source. With the increase of global environmental pollution and the greenhouse effect, wind power technology is becoming the mainstream in current research [1-3]. Wind turbines are being developed and utilized on a large-scale due to their mature technology of energy conversion, low cost of power generation, and broad prospects for energy development [4-6].

The tower of the wind turbine is very high, and the working environment of the wind turbine is harsh $[7,8]$. If the wind turbine fails, it will be more difficult to repair $[9,10]$. In order to improve the stability of the wind turbine at work and prolong the working life, the inspection and testing of the key parts of the wind turbine has important application value $[11,12]$.

The stability and reliability of bearings in wind turbines is one of the key factors for the long service life of wind turbines. There are many equipment using bearings in wind turbines, mainly including main bearings, pitch bearings, and yaw bearings $[13,14]$. Among them, the design, manufacture and inspection technology of pitch bearing and yaw bearing have been developed maturely. But the test technology of the main bearing is not perfect, especially for the test equipment of the main bearing of the $2 \mathrm{MW}-6 \mathrm{MW}$ large-scale wind turbine. At present, only a few developed countries have mastered the test technology of the bearings of large wind turbine. ROTHE ERDE has specially developed a slewing bearing test bench for wind power slewing bearings, which can realize the vertical installation of slewing bearings, and at the same time simulate large radial forces based on the load-bearing characteristics of the slewing bearings, testing the comprehensive performance of the bearings [15]. SKF has developed a set of testing equipment about wind power 
bearing. The axial load applied to the bearing during testing can reach twice actual load, and the test speed of the test bearing can reach $60 \mathrm{rpm}$, which is three times the operating speed of the bearing under actual working conditions. In addition to simulating the actual working conditions of the bearing, this equipment can also detect the friction performance, elastic deformation, bearing temperature and other parameters of the test bearing [16]. The French LGMT laboratory has developed a bearing testing machine that is mainly used to analyze the load distribution of pitch and yaw bearings under static loads [17].

In the bearing inspection, many scholars and experts have given the bearing inspection methods in different applicable fields. Kusiak and Verma developed a bearing failure prediction model by analyzing the historical data of wind turbines [18]. This model was formed by collecting data from 24 wind turbines using a neural network algorithm, and the fault detection accuracy of the model on different wind turbines is $97 \%$. Barszcz and Sawalhi introduced the application of minimum entropy deconvolution (MED) in the detection and diagnosis of rolling bearing faults [19]. Two main cases were presented to illustrate the benefits of MED technology. The first is applied on a test bench of fan blades, and the second is applied on a wind turbine with inner ring failure. Zhu et al. proposed a transfer learning method based on multiple layer perceptron (MLP) by using Hidden Markov model (HMM) to automatically detect state changes [20]. He used this method to conduct an experimental study on the remaining useful life (RUL) of the bearing, which confirmed the effectiveness of the method. Cao et al. proposed a data-driven method that combines interval whitenization method and Gaussian process (GP) algorithms to predict the RUL of wind turbine bearings [21]. Hu et al. proposed an engineering CI (ECI) that combines the energy and kurtosis representation of the vibration signal [22]. Through the analysis of the failure test data of the bearing during operation, it is shown that ECI can evaluate the overall condition of the bearing and detect the real-time performance of the bearing. The above literatures are all about the study of predicting and detecting bearings, and different detection methods are proposed, but these literatures do not thoroughly consider the force state of the bearing under actual working conditions, such as the wind turbine main bearing under the influence of the non-directional wind.

For bearing inspection and analysis, the actual load borne by the bearing must be fully considered, especially the main bearing of the wind turbine [23, 24]. The load received by the wind turbine in the actual working process is constantly changing with the influence of natural wind [25]. The main bearing is the core component of the wind turbine, and its function is to support the rotation of the main shaft and reduce the frictional influence caused by the rotation of the main shaft $[26,27]$. Therefore, the quality of the main bearing will directly determine the performance of the entire equipment. It is very important to test the bearing by simulating working conditions on the main bearing of the wind turbine.

Although many literatures take test benches to carry out loading experiments on bearings to detect bearings or analyze dynamic characteristics of bearings [28-30], the size of these tested bearings is too small to meet the test standards for the main bearings of large wind turbines. Therefore, this study proposes a loading method based on the test-bed to detect the bearing, that is, according to actual load of the main bearing of large-scale wind turbine, eight hydraulic cylinders in test-bed are used to load to simulate the bearing's ultimate load, and the DC motor runs and drives the main bearing to rotate. Finally, the actual working condition of the main bearing is simulated in test bench.

This paper is structured into the following sections: Section 2 analyzes the loading model of the installation method of double-row and single-row tapered roller bearings, and transfers the force system at the center of the fan hub to the reference plane of the bearing; In Section 3, the force system of the bearing on the reference plane is transferred to the eight hydraulic cylinders of the test bench, and the force system loading model of the test bench is established; In Section 4, the loading experiment of the main bearing of wind turbine is carried out, and the radial displacement, axial displacement and temperature changes of the bearing are recorded by sensors. Section 5 summarizes the study and provides the conclusions.

\section{Method of Force System Transformation of Wind Turbine}

The main bearing at the connection between the generator rotor and the hub is an important part of the wind turbine, and most of them are tapered roller bearings. The main bearing is located at the front end of the entire transmission chain. The supporting force of the main shaft and the wind wheel is mainly provided by the main bearing, so the stability of the main bearing structure is an important guarantee for the normal operation of the entire mechanism. The main bearing adopts double-row tapered roller bearings or single-row tapered roller bearings in the structural form, and its installation methods are shown in Figure 1 and Figure 2.

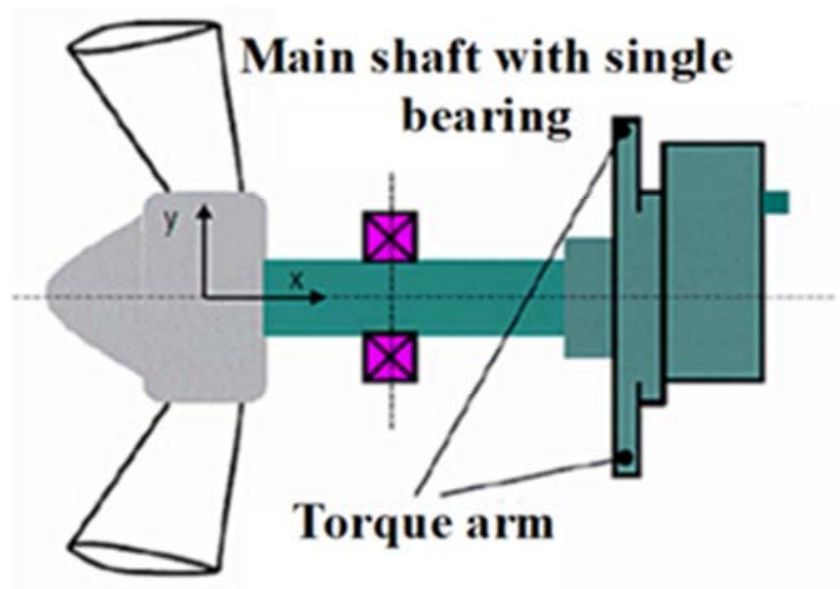

Figure 1. The installation of double row tapered roller bearings. 


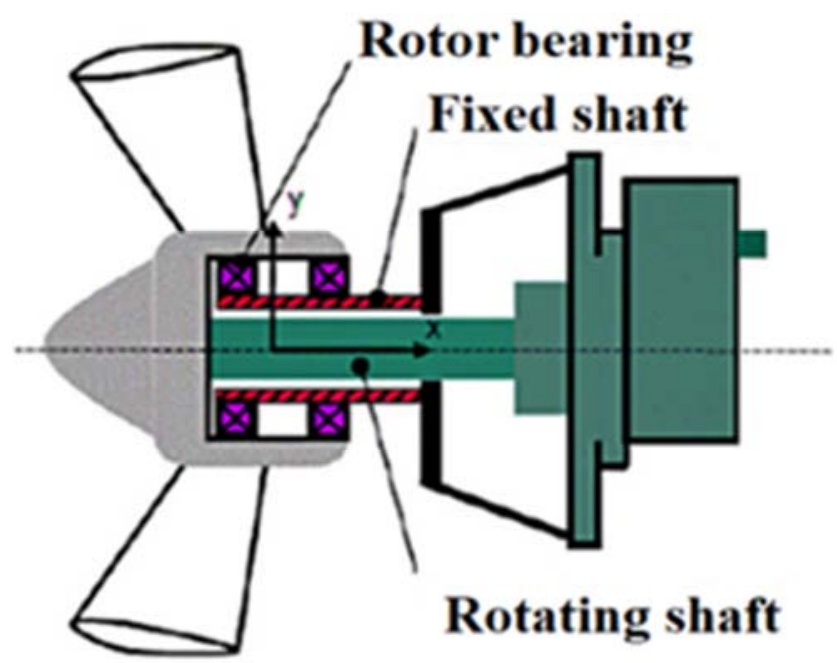

Figure 2. The installation of single row tapered roller bearings.

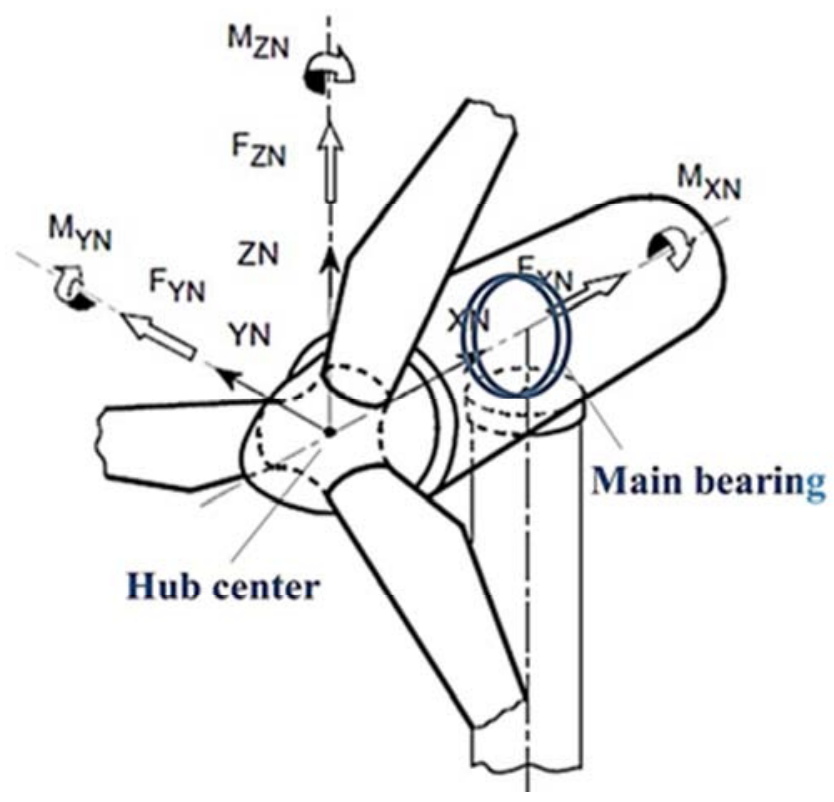

Figure 3. The Mechanical model of wind turbine under actual working condition.

\subsection{Analysis of Mechanical Model of Double-Row Tapered Roller Bearing}

The mechanical model of the wind turbine under actual working conditions is shown in Figure 3. The main bearing bears the radial force, overturning moment generated by the weight of the hub and blades, and the axial force, radial force, and overturning moment generated by the interaction between the wind and the blades. Since the loading center of the test bench is different from the center of the wheel hub during the test, when testing the bearing, the actual force on the main bearing of the wind turbine and the force on the test bench are modeled first. Then according to the theory of the space force system, equivalent decomposition and transformation are carried out to convert the load on the center of the wind turbine hub to the load system of the tested bearing reference plane and the test bench. The mechanical model of the center force system of the wind turbine hub converted to the reference surface force system of the main bearing is shown in Figure 4.

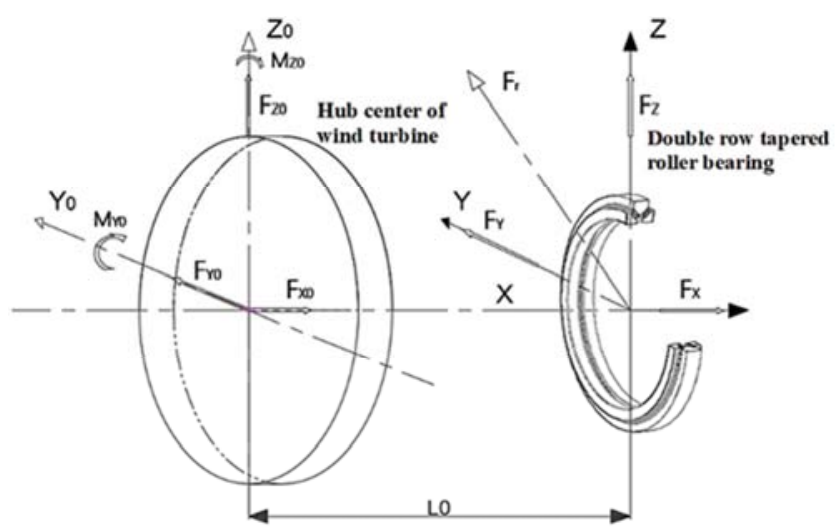

Figure 4. The Mechanical model of double-row tapered roller bearing.

From the equivalent mechanical model in Figure 4, composite $\sum F_{X}$ in the $\mathrm{X}$-axis direction, composite $\sum F_{Y}$ in the $\mathrm{Y}$-axis direction, composite $\sum F_{Z}$ in the $\mathrm{Z}$-axis direction, composite $\sum M_{Y}$ in the $\mathrm{Y}$-axis direction, and composite $\sum M_{Z}$ in the Z-axis direction. The following conversion relationship can be obtained.

$$
\begin{gathered}
F_{X}=F_{X 0} \\
F_{Y}=F_{Y 0} \\
F_{Z}=F_{Z 0} \\
M_{Y}=F_{Z 0} \cdot L_{0}+M_{Y 0} \\
M_{Z}=-F_{Y 0} \cdot L_{0}+M_{Z 0}
\end{gathered}
$$

Where $F_{X}$ is the $\mathrm{X}$-axis load of the test bearing $(\mathrm{N}), F_{Y}$ is the $\mathrm{Y}$-axis load of the test bearing $(\mathrm{N}), F_{Z}$ is the Z-axis load of the test bearing $(\mathrm{N}), M_{Y}$ is the Y-axis torque of the test bearing $(\mathrm{N} \cdot \mathrm{m}), M_{Z}$ is the $\mathrm{Z}$-axis torque of the test bearing $(\mathrm{N} \cdot \mathrm{m})$ and LO is the distance from the center of the wind turbine hub to the test bearing $(\mathrm{m})$.

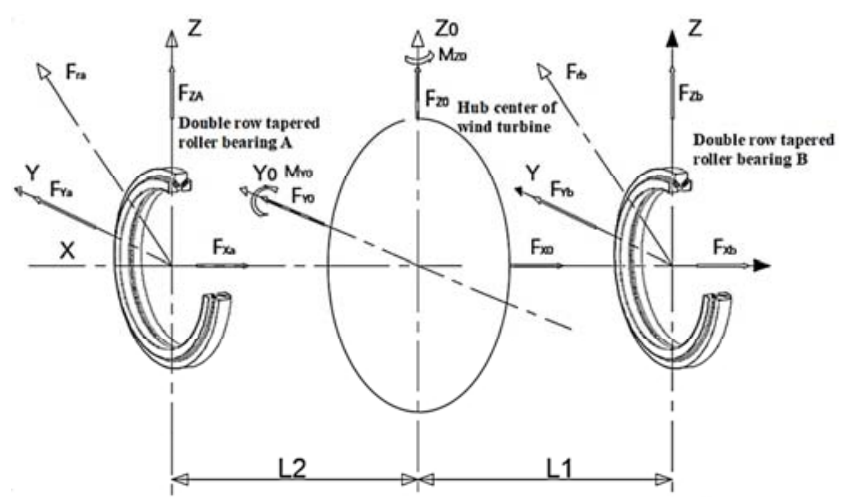

Figure 5. The Mechanical model of single-row tapered roller bearing.

\subsection{Analysis of Mechanical Model of Single-Row Tapered Roller Bearing}

The installation method of the transmission bearing of the wind turbine adopting single-row tapered roller bearing is 
shown in Figure 2. The single-row tapered roller bearings are located on both sides of the center of the wind turbine hub, and the force of the two tested bearings is relatively even. For this type of installation, the load on the center of the wind turbine hub is converted to the reference surface of the test bearing A and the test bearing B, as shown in Figure 5.

The force conversion is carried out by the mechanical model in Figure 5 and the space force system theory in theoretical mechanics. The equivalent mechanical model of the Y-axis force and the Z-axis force is shown in Figure 6 and Figure 7 respectively.

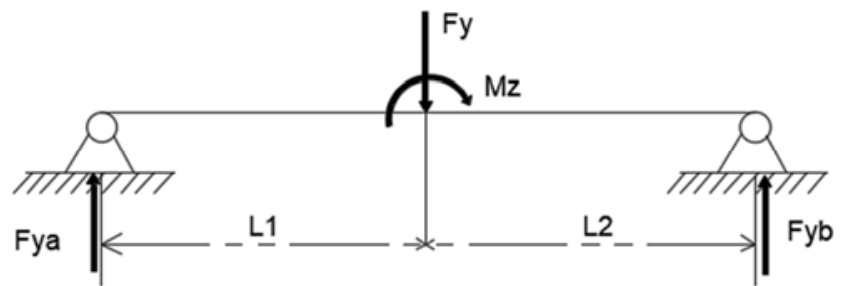

Figure 6. The equivalent mechanical model of Y-axis force.

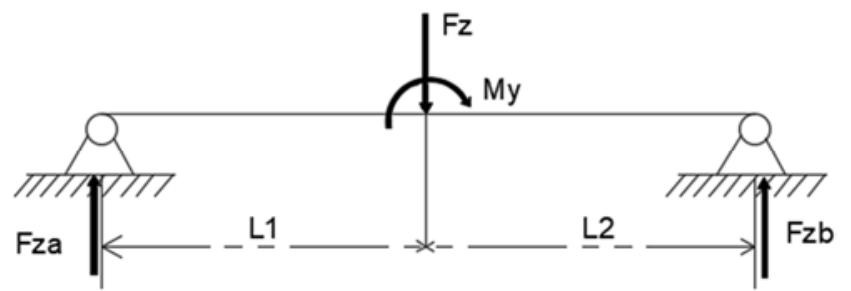

Figure 7. The equivalent mechanical model of Z-axis force.

According to the balance condition $\left(\sum F_{Y}=0\right.$ and $\sum M_{A}=$ 0 ), the equivalent transformation of $Y$-axis force is as follows.

$$
\begin{gathered}
F_{y a}+F_{y b}=F_{y} \\
M_{z}+F_{y} \cdot L_{1}-F_{y b} \cdot\left(L_{1}+L_{2}\right)=0
\end{gathered}
$$

According to the balance condition $\left(\sum F_{Z}=0\right.$ and $\sum M_{B}=$ 0 ), the equivalent transformation of $Z$-axis force is as follows.

$$
\begin{gathered}
F_{z a}+F_{z b}=F_{z} \\
M_{y}+F_{z} \cdot L_{1}-F_{z b} \cdot\left(L_{1}+L_{2}\right)=0
\end{gathered}
$$

In addition, the $\mathrm{X}$-axis force of the test bearing is equal to the $\mathrm{X}$-axis force of the hub center.

$$
F_{x a}=F_{x b}=F_{X 0}
$$

Finally, the force of single-row tapered roller bearings A $\left(F_{x a}, F_{y a}\right.$ and $\left.F_{z a}\right)$ and $\mathrm{B}\left(F_{x b}, F_{y b}\right.$ and $\left.F_{z b}\right)$ can be obtained.

\section{Method of Force System Transformation of Test Bench}

Under working conditions, the main bearing of wind turbine has a complicated stress state. In order to simulate the loading condition of the bearing under normal operating conditions, after the force on the center of the wind turbine hub is transformed into the main bearing in Section 2, it is necessary to further transform the force on the main bearing to the test loading system of the test bench.

\subsection{Working Principle of Wind Turbine Bearing Test Bed}

The overall structure of the bearing test-bed is shown in Figure 8. The main structure of the test-bed includes moving component, flip component, loading component, underframe component, test bearing and driving component. The function of the flip component is to replace the bearing, as shown in Figure 9. The bearing under test is loaded in the loading frame, as shown in Figure 10. The driving component is driven by an $80 \mathrm{~kW}$ DC motor to power the spindle to rotate, and the spindle turns the bearing.

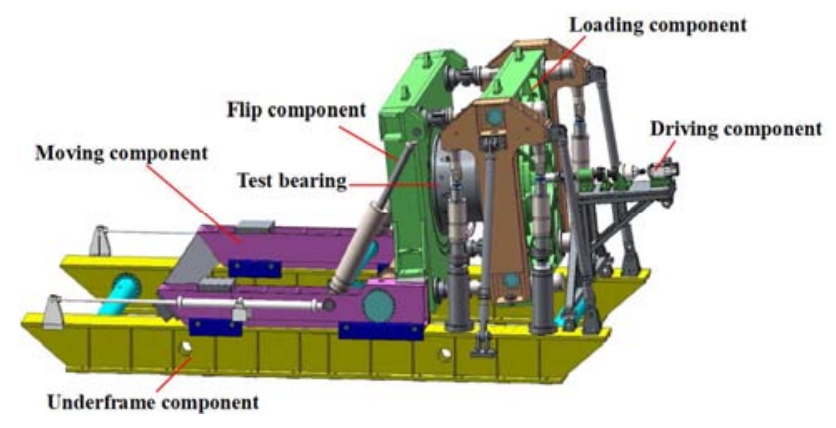

Figure 8. The overall structure of bearing loading test bench.

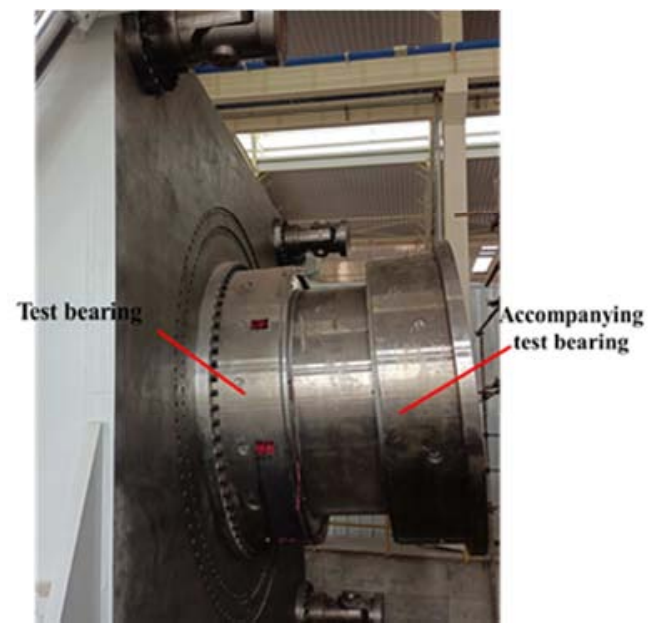

Figure 9. The flip component of bearing test bench.

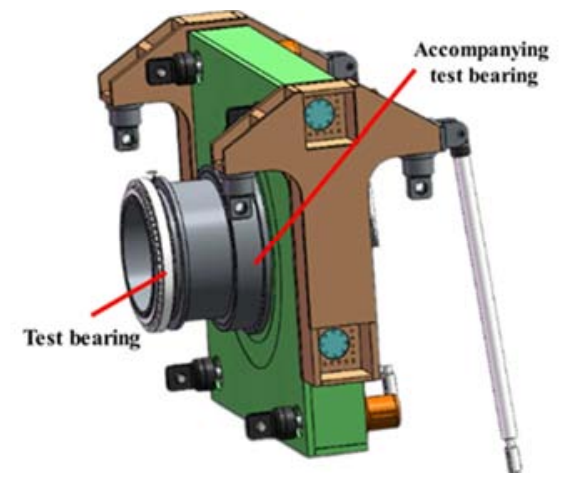

Figure 10. The loading component of bearing test bench. 


\subsection{Combined Loading Method of Axial Hydraulic Cylinder and Radial Hydraulic Cylinder}

The core of the test bench is the loading component. The force applied to the bearing by the loading frame assembly comes from the eight hydraulic cylinders mounted on the main frame, four of which are radial hydraulic cylinders (R1, R2, R3 and R4), and the other four are axial hydraulic cylinders (A1, A2, A3 and A4), as shown in Figure 11 and Figure 12. $\mathrm{Fa}-\mathrm{Fh}$ are respectively the loading pressure of the corresponding hydraulic cylinder.

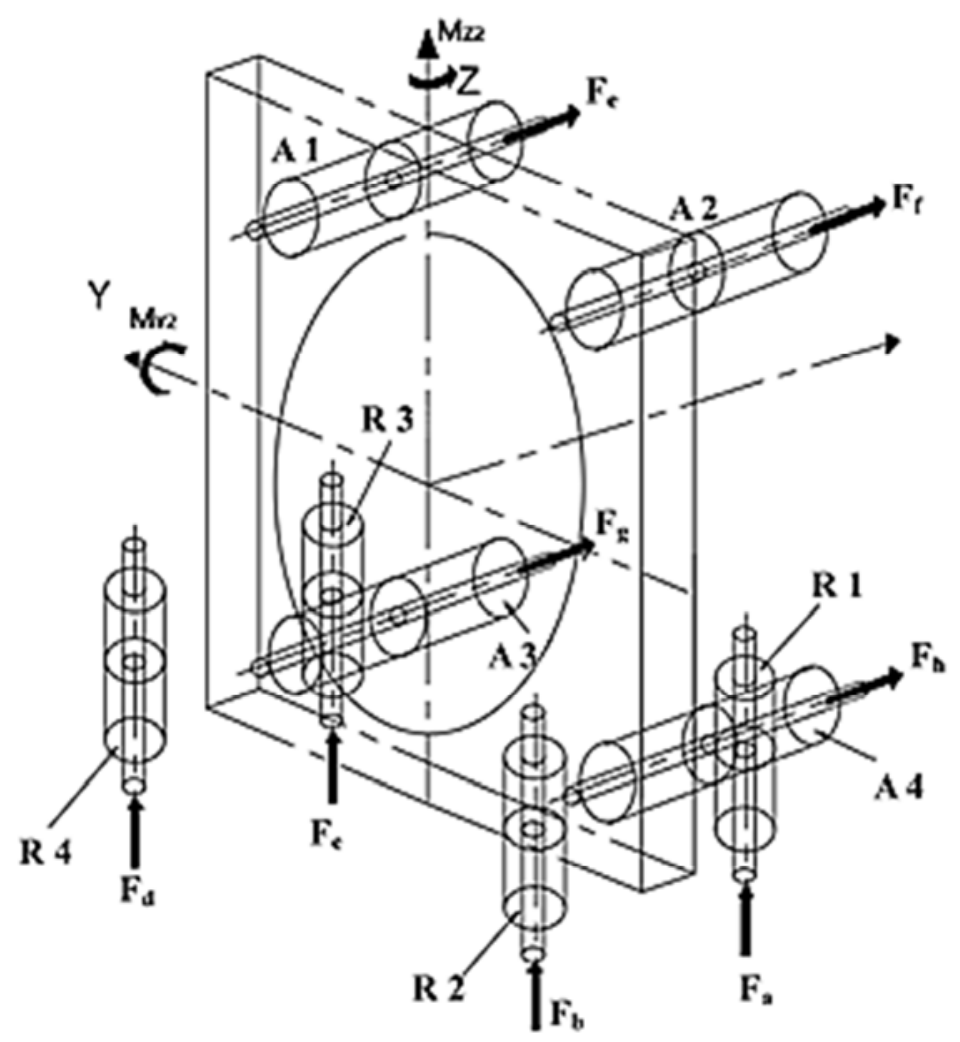

Figure 11. The hydraulic cylinder loading model.

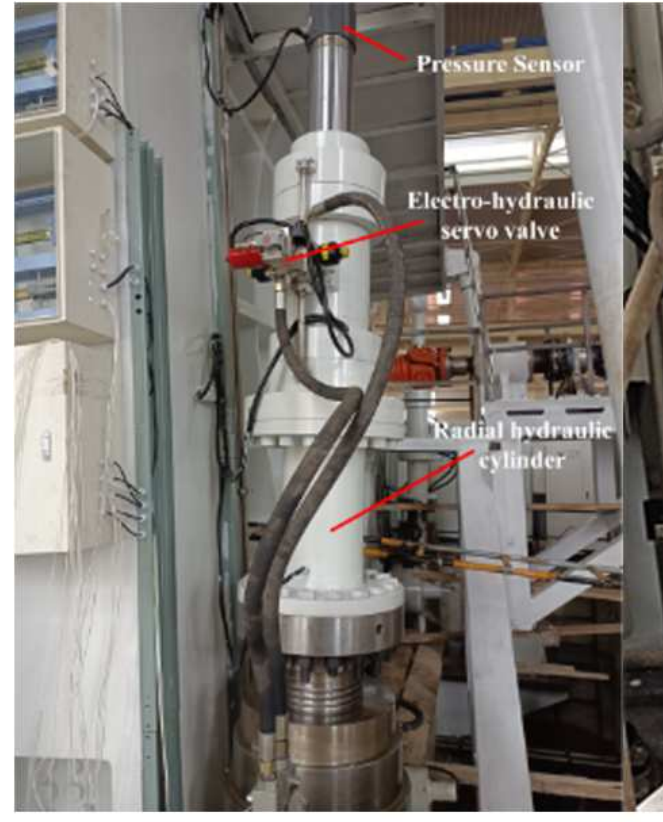

(a) The radial hydraulic cylinder.

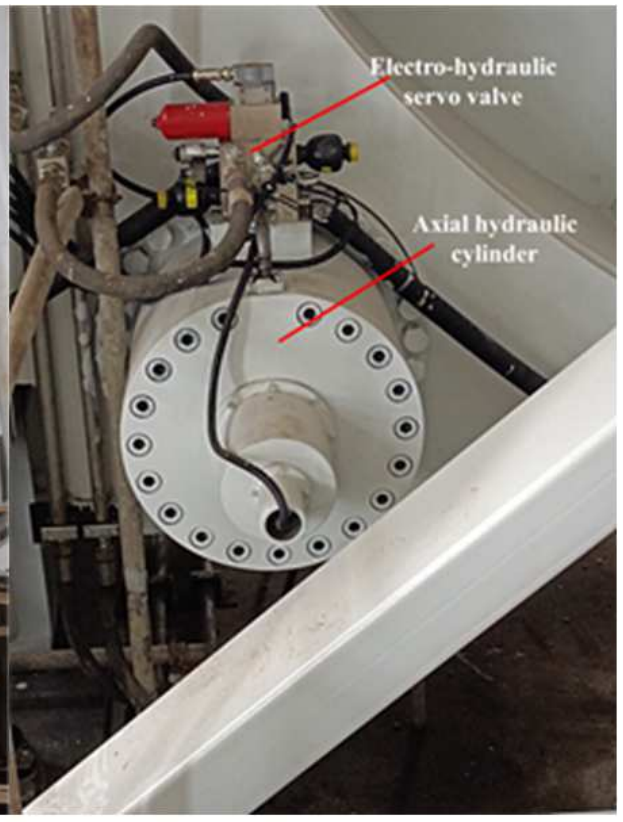

(b) The axial hydraulic cylinder.

Figure 12. Loading method of loading component in the bearing test bench.

The test bench adopts the coordinated loading method of axial and radial hydraulic cylinders, with 4 cylinders in the axial 
direction and 4 cylinders in the radial direction as a dynamic system to load the test bearing. The loading calculation model is shown in Figure 13, and according to the equilibrium conditions of the model, the Equation set (11) can be established.

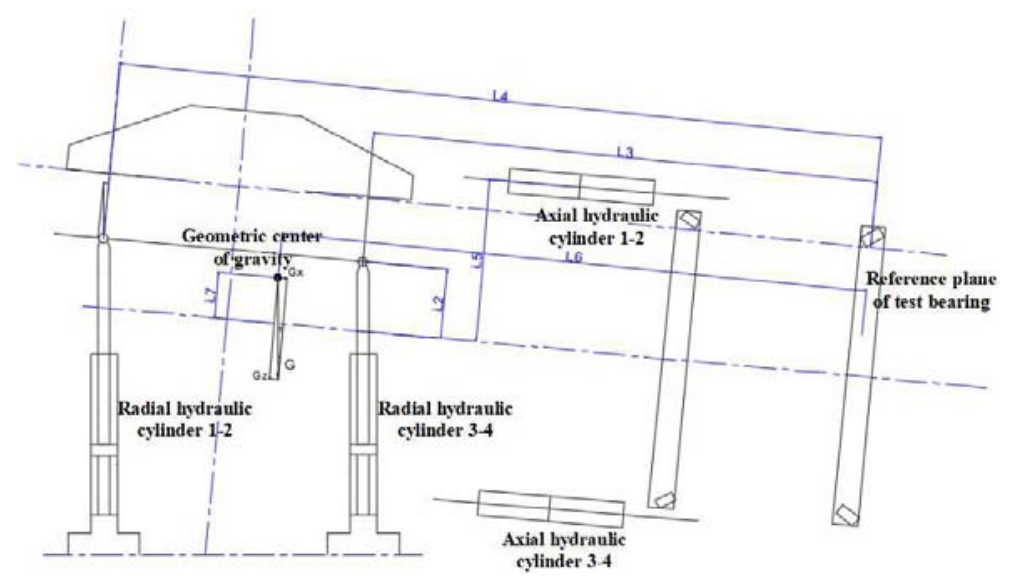

Figure 13. The calculation principle of the combined loading mechanical model.

$$
\left\{\begin{array}{c}
F_{a}+F_{b}+F_{c}+F_{d}=\frac{F_{Z 0}+G \cdot \cos \alpha}{\cos \alpha} \\
-\sin \alpha \cdot F_{a}-\sin \alpha \cdot F_{b}-\sin \alpha \cdot F_{c}-\sin \alpha \cdot F_{d}+F_{e}+F_{f}+F_{g}+F_{h}=F_{X 0}-G \cdot \alpha \\
\left(L_{4} \cdot \cos \alpha-L_{2} \cdot \sin \alpha\right) F_{a}+\left(L_{4} \cdot \cos \alpha-L_{2} \cdot \sin \alpha\right) F_{b}+\left(L_{3} \cdot \cos \alpha-L_{2} \cdot \sin \alpha\right) F_{c}+\left(L_{3} \cdot \cos \alpha-L_{2} \cdot \sin \alpha\right) F_{d} \\
+L_{5} F_{e}+L_{5} \cdot F_{f}-L_{5} \cdot F_{g}-L_{5} \cdot F_{h}=\left(M_{Y 0}+F_{Z 0} \cdot L-G \cdot \sin \alpha L_{7}+G \cdot \cos \alpha \cdot L_{6}\right) \\
L_{5} F_{e}-L_{5} F_{f}+L_{5} F_{g}-L_{5} F_{h}=M_{Z 0}-F_{Y 0} \cdot L \\
F_{a}-F_{b}=0 \\
F_{c}-F_{d}=0
\end{array}\right.
$$

Where $\alpha$ is the inclination angle of the bearing axis and the horizontal plane $\left(^{\circ}\right), \mathrm{G}$ is the gravity of the loading component of the test bench $(\mathrm{kN}), \mathrm{L}$ is the distance from $\mathrm{G}$ axial hydraulic cylinder to test bearing (m) (L2-L7 is shown in Figure 12), $F_{X 0}, F_{Y 0}, F_{Z 0}, M_{Y 0}$ and $M_{Z 0}$ are the $\mathrm{X}$-axis force $(\mathrm{N}), \mathrm{Y}$-axis force $(\mathrm{N}), \mathrm{Z}$-axis force $(\mathrm{N}), \mathrm{Y}$-axis torque $(\mathrm{N} \cdot \mathrm{m})$, and $\mathrm{Z}$-axis torque $(\mathrm{N} \cdot \mathrm{m})$ of the test bearing respectively.

According to the coefficient of the equation, the system of non-homogeneous linear Equations (12) is established, and solve it to get Equation (13).

\section{Experiment and Results}

\subsection{Technical Requirements for Bearing Loading Experiment}

According to the actual working conditions of the main bearing in wind turbine, the experimental process should meet the following requirements:

(1) After the test bearing is installed, the inclination angle of the bearing axis and the horizontal plane is $5^{\circ}$ $\left(\alpha=5^{\circ}\right)$.

(2) The axial load of the tested bearing during loading should be greater than $1200 \mathrm{KN}$, radial load greater than $4000 \mathrm{KN}$, and overturning moment greater than 30000 $\mathrm{kN} \cdot \mathrm{m}$.

(3) The test-bed can realize the stepless speed regulation of bearing in 0-20 rpm.

(4) The deformation and displacement of bearing should not exceed its limit.

The bearing selected for testing in this study is the main bearing of a $2.5 \mathrm{MW}$ wind turbine. Its type is a double-row tapered roller bearing with an outer diameter of $2500 \mathrm{~mm}$, an inner diameter of $2000 \mathrm{~mm}$, and a height of $320 \mathrm{~mm}$. The maximum deformation or displacement that the bearing can withstand is $5 \mathrm{~mm}$. The $2.5 \mathrm{MW}$ wind turbine hub center load is shown in Table 1.

According to Table 1 and equations (1) - (5), the load on the hub center of the $2.5 \mathrm{MW}$ wind turbine main bearing is converted to the test bearing reference plane, and the conversion calculation results are shown in Table 2.

According to Table 2 and Equation set (13), the loading data of the hydraulic cylinder of the main bearing test bench of the wind turbine can be obtained, as shown in Table 3. Finally, through two mechanical conversion models, the hub center load has been converted to the axial and radial hydraulic cylinder load of the test bench.

\subsection{Analysis of Results}

The test bearing outer ring surface is equipped with 8 displacement sensors, of which 4 displacement sensors are used to measure the axial displacement of the bearing, and the other 4 are used to measure the radial displacement of the bearing. In addition, a temperature sensor is installed to measure the real-time temperature of the bearing.

During the test, the hydraulic cylinders of the loading components are pressurized (that is, eight hydraulic cylinders 
are pressurized to reach the value required in Table 3), and the torque of the drive motor is changed at the same time. The sensors on the test bench continuously transmit data to the console and record the results.

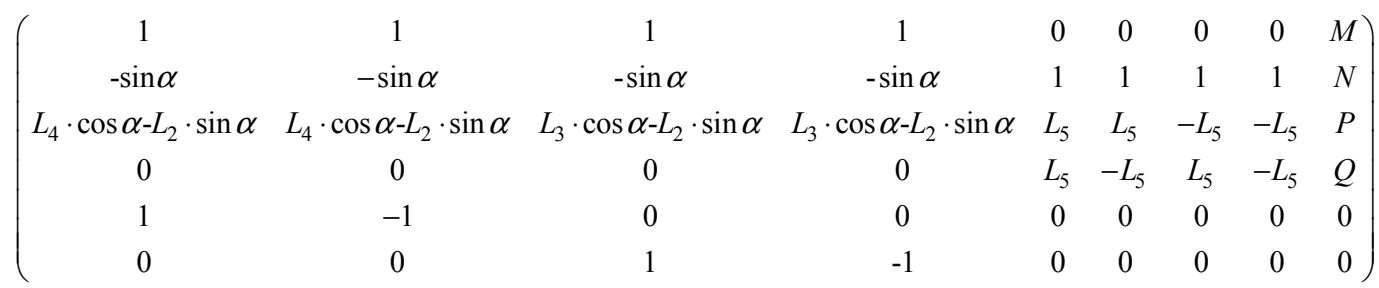

$$
\left(\begin{array}{c}
F_{a} \\
F_{b} \\
F_{c} \\
F_{d} \\
F_{e} \\
F_{f} \\
F_{g} \\
F_{h}
\end{array}\right)=\left(\begin{array}{c}
0.5 M-F_{d} \\
0.5 M-F_{d} \\
F_{d} \\
F_{d} \\
-0.6078 M+0.2 P+0.2 Q+0.948 F_{d}+F_{h} \\
0.6513 M+0.5 N-0.2 Q-F_{h} \\
0.6513 M+0.5 N-0.2 P-0.948 F_{d}-F_{h} \\
F_{h}
\end{array}\right)
$$

Where $M=\left(F_{Z 0}+G \cdot \cos 5^{\circ}\right) / \cos 5^{\circ}, \quad N=F_{X 0}-G \cdot \sin 5^{\circ}, \quad P=M_{Y 0}+F_{Z 0} \cdot L_{0}-G \cdot \sin 5^{\circ} \cdot L_{7}+G \cos 5^{\circ} \cdot L_{6}$ and $Q=M_{Z 0}-F_{Y 0} \cdot L_{0}$.

Table 1. The load on the hub center of the main bearing of $2.5 \mathrm{MW}$ wind turbine.

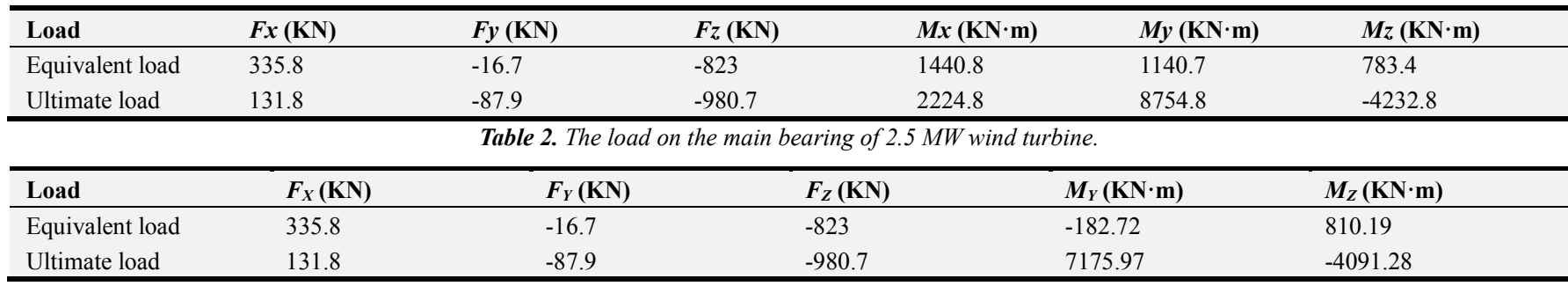

Table 3. The coordinated loading of axial and radial hydraulic cylinders for $2.5 \mathrm{MW}$ bearing loading test.

\begin{tabular}{lllllllll}
\hline Load & \multicolumn{2}{l}{ Radial hydraulic cylinder } & \multicolumn{5}{l}{ Axial hydraulic cylinder } \\
\hline Cylinder load & $\mathbf{R} 1\left(\boldsymbol{F}_{a}\right)(\mathbf{K N})$ & $\mathbf{R 2}\left(\boldsymbol{F}_{b}\right)(\mathbf{K N})$ & $\mathbf{R 3}\left(\boldsymbol{F}_{c}\right)(\mathbf{K N})$ & $\mathbf{R 4}\left(\boldsymbol{F}_{d}\right)(\mathbf{K N})$ & $\mathbf{A 1}\left(\boldsymbol{F}_{e}\right)(\mathbf{K N})$ & $\mathbf{A 2}\left(\boldsymbol{F}_{f}\right)(\mathbf{K N})$ & $\mathbf{A 3}\left(\boldsymbol{F}_{g}\right)(\mathbf{K N})$ & $\mathbf{A 4}\left(\boldsymbol{F}_{h}\right)(\mathbf{K N})$ \\
\hline Equivalent load & 848 & -300 & 848 & -300 & 1148 & -1429 & -856 & 1400 \\
\hline
\end{tabular}

\subsubsection{Experimental Results of Wind Turbine Bearing at Constant Torque Starting}

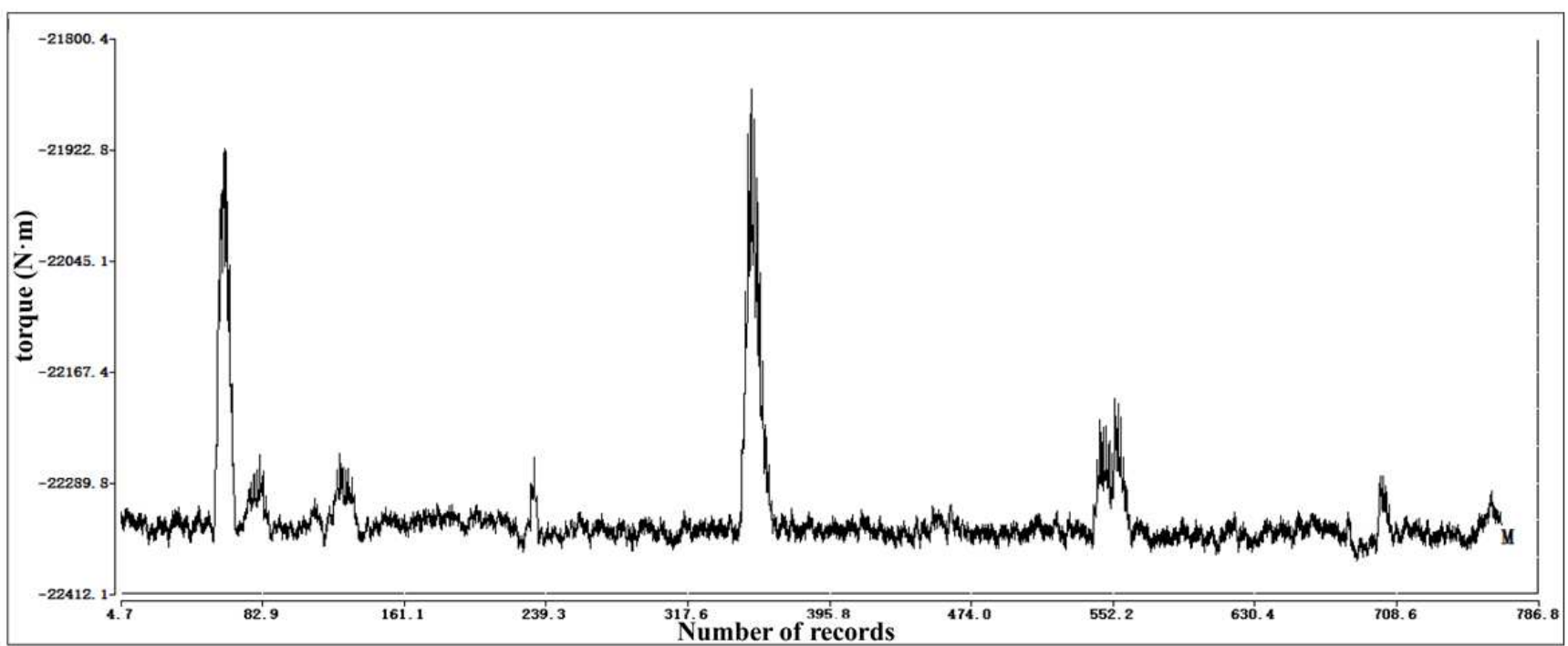

Figure 14. The torque change of the test bearing at constant torque. 
When starting with a constant torque (see Figure 14), the axial displacement 1, 3, and 4 of the bearing have an obvious decreasing trend. After the record number is 239 , the axial displacement exhibits periodic changes, and the maximum axial displacement is $4.37 \mathrm{~mm}$ (see Figure 15). The radial displacements 1 and 2 of the bearing gradually decrease after the constant rotation starts, and the radial displacement 3 gradually increases (see Figure 16). The four radial displacements change periodically with the rotation of the bearing after the recorded number is 239 .

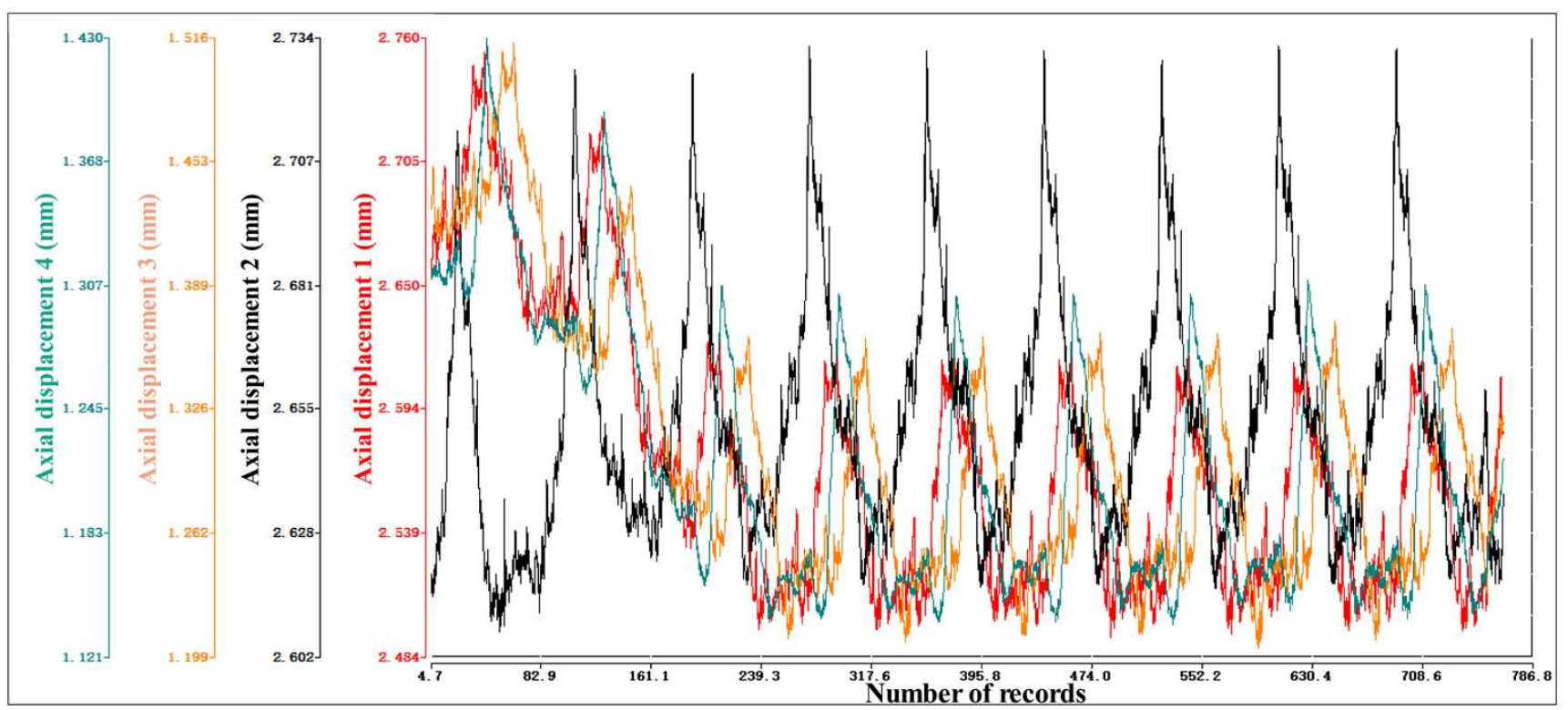

Figure 15. The axial displacement of the test bearing at constant torque.

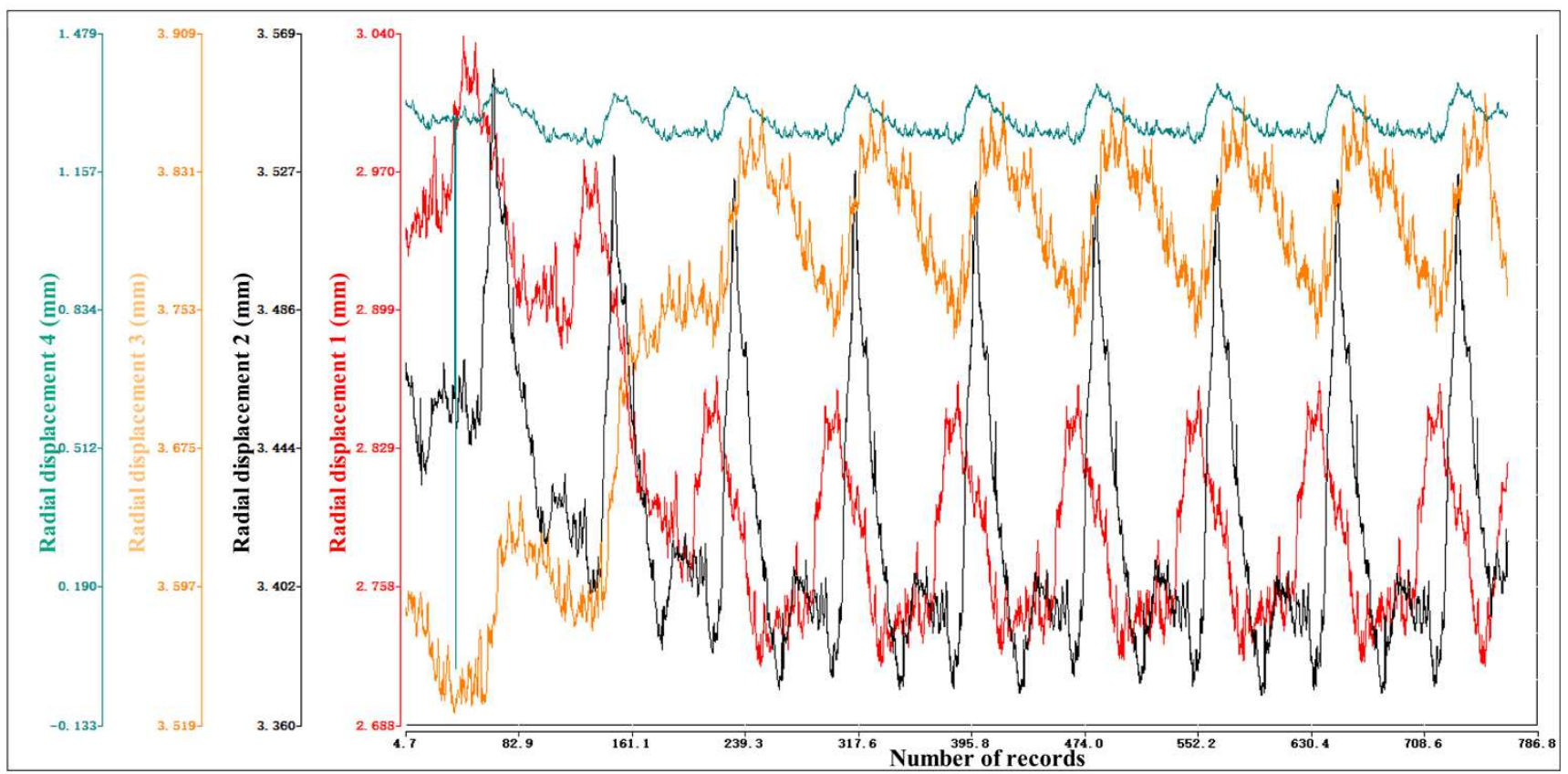

Figure 16. The radial displacement of the test bearing at constant torque.

\subsubsection{Experimental Results of Wind Turbine Bearing When Torque Increases and Decreases}

When the loading device is running stably, increasing the motor torque, the radial displacement and axial displacement of the test bearing change periodically (see Figure 17-18).

When the loading device is running stably, decreasing the motor torque, the radial displacement and axial displacement of the test bearing change periodically (see Figure 19-20).

Both radial and axial displacements are within $5 \mathrm{~mm}$ under acceleration and deceleration conditions, which indicates that the bearing can still operate stably when the wind speed changes sharply. 


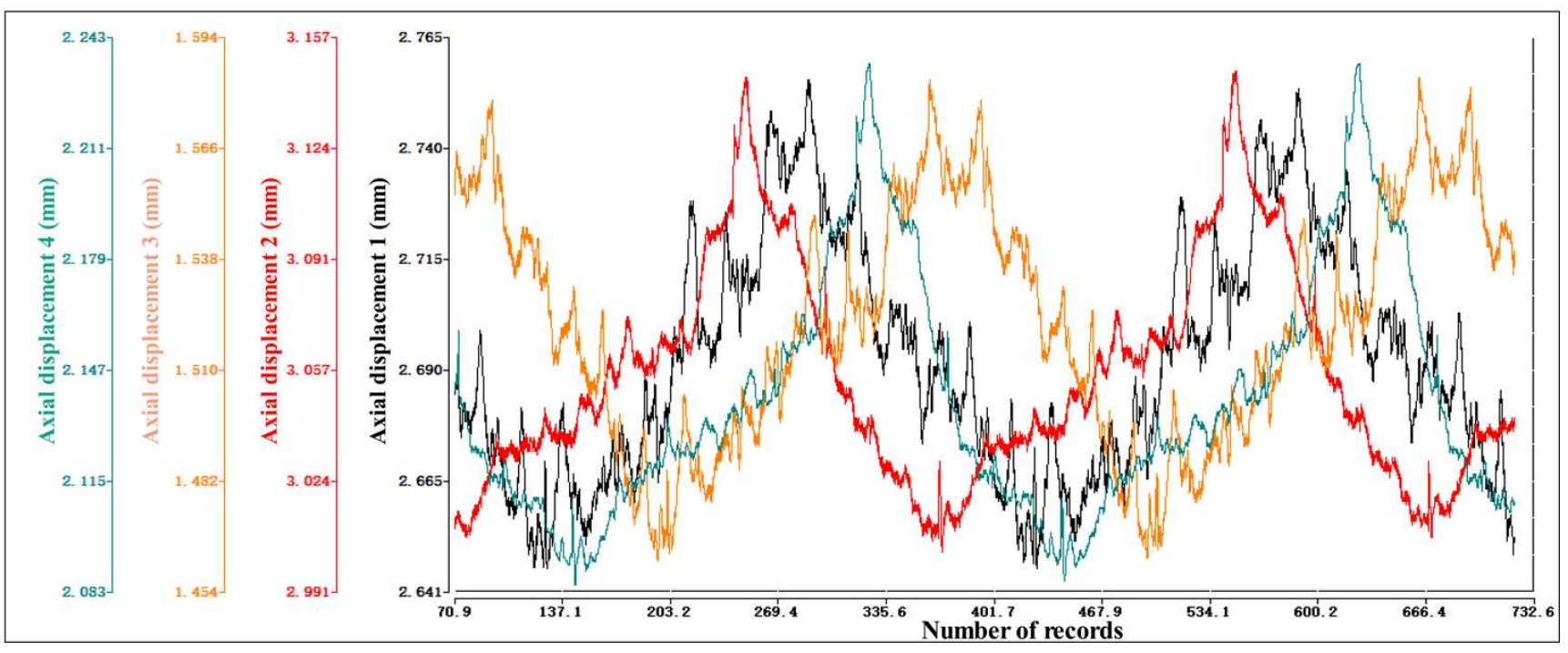

Figure 17. The axial displacement of the tested bearing when the torque increases.

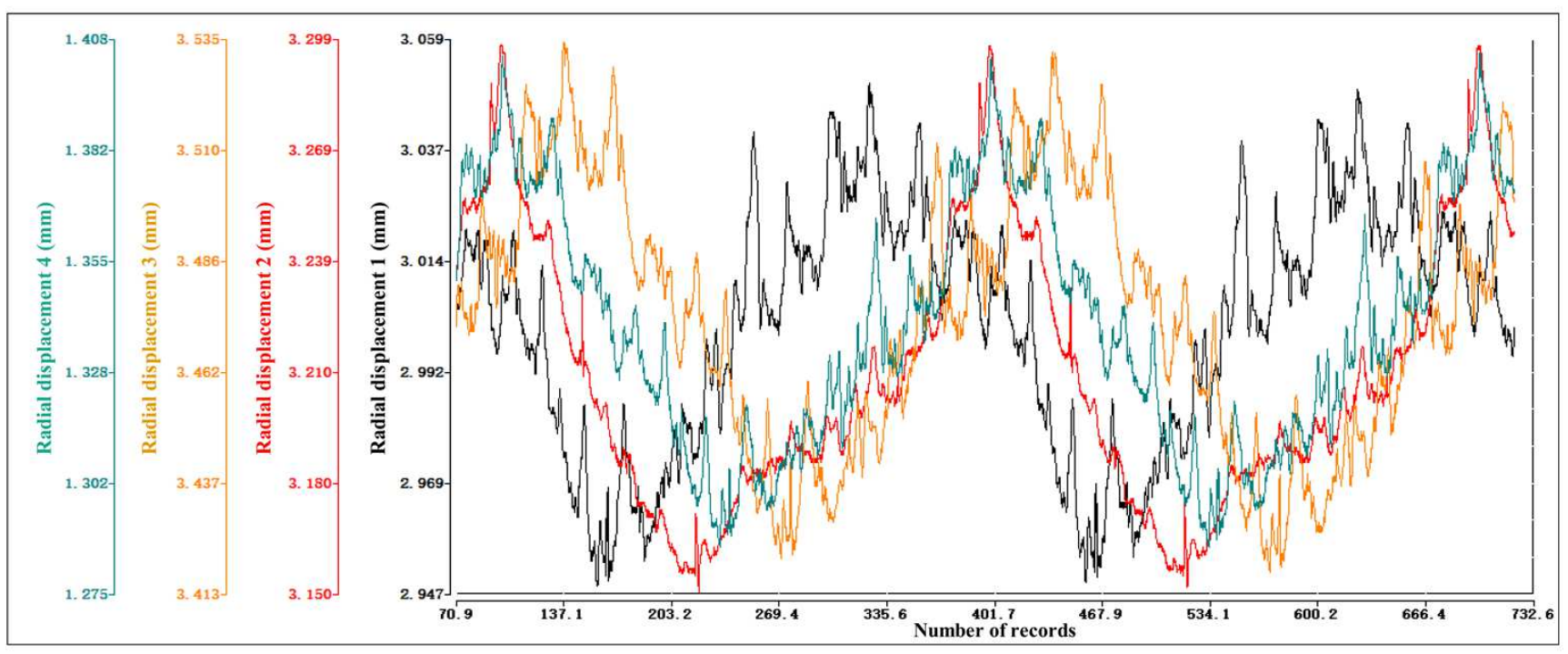

Figure 18. The radial displacement of the tested bearing when the torque increases.

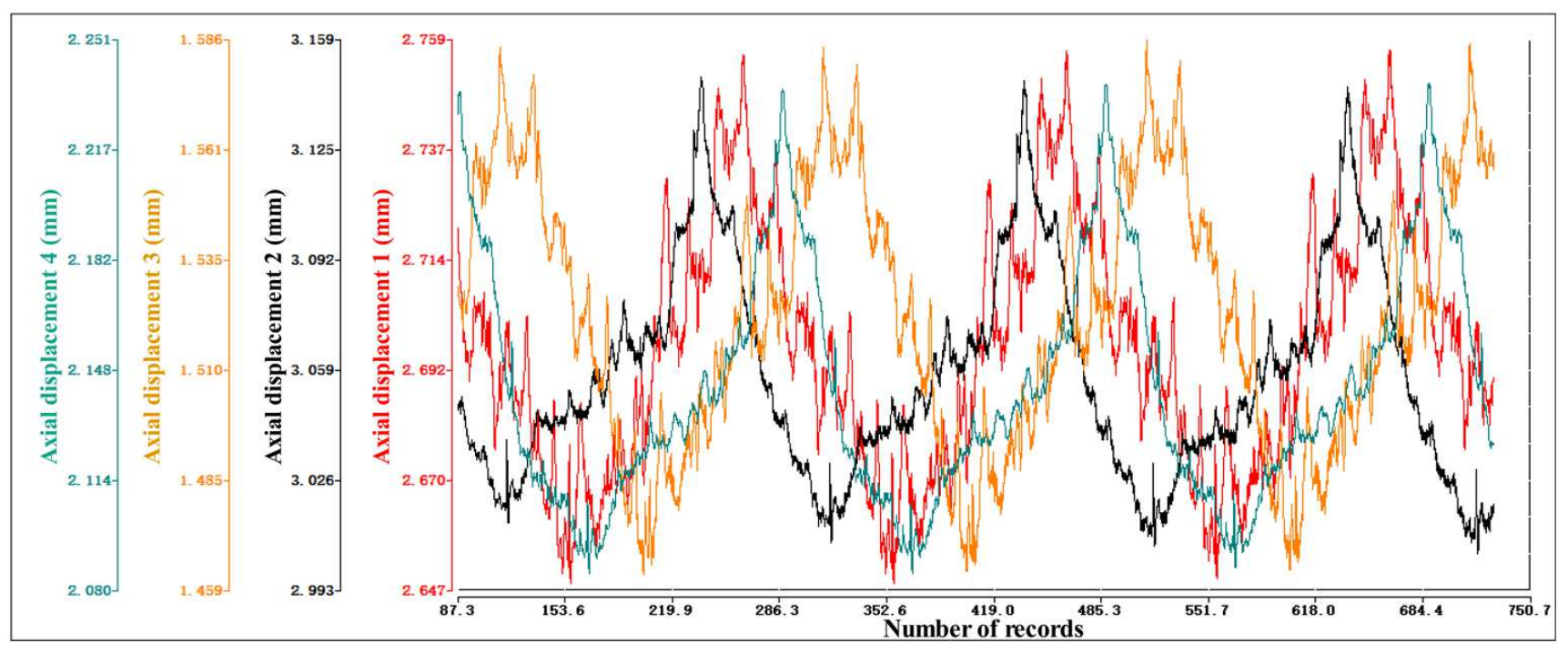

Figure 19. The axial displacement of the tested bearing when the torque decrease. 


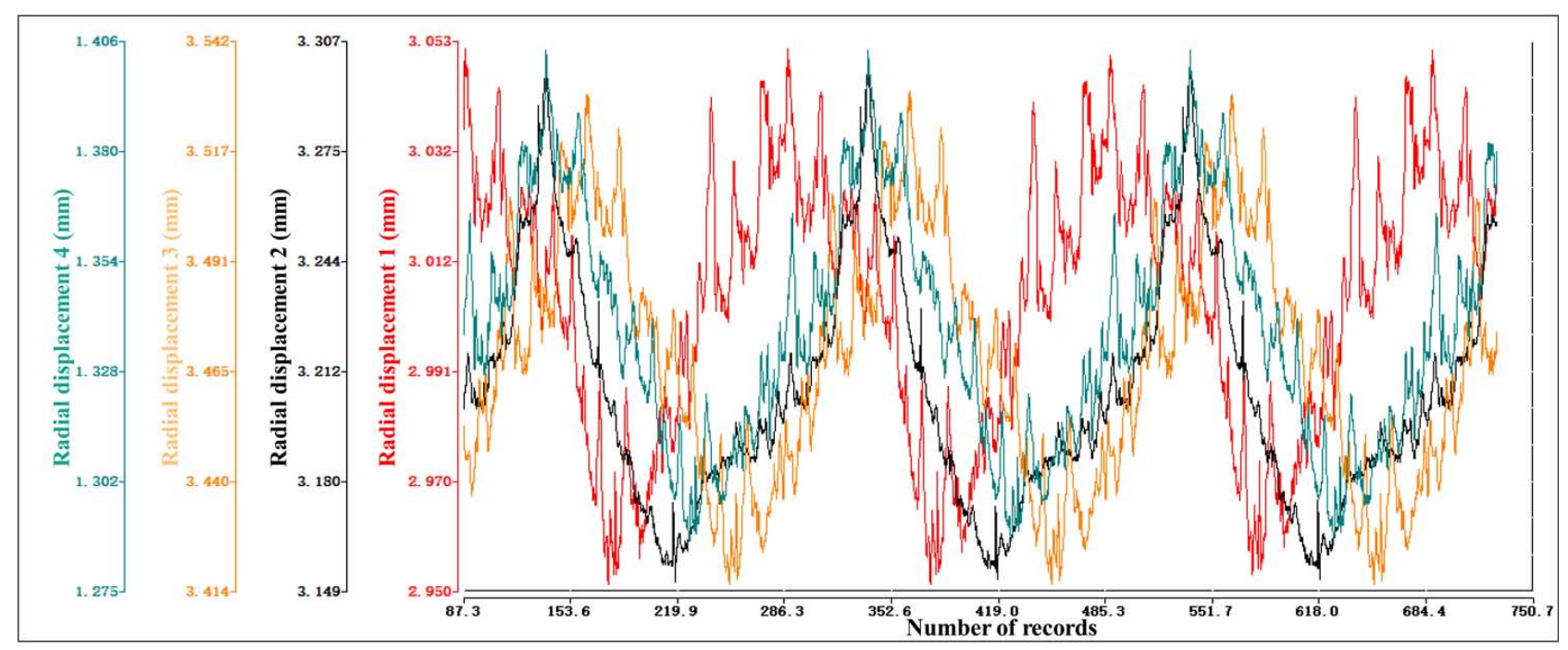

Figure 20. The radial displacement of the tested bearing when the torque decrease.

\subsubsection{Experimental Results of Temperature Change of Wind Turbine Bearing}

After the test bench runs smoothly, the temperature recording points of the inner and outer rings of the test bearing in 24 hours are selected. The recording results are shown in Table 4. The results showed that the temperature of the outer ring of the bearing was significantly lower than that of the inner ring, and the average temperature of the outer ring was $29^{\circ} \mathrm{C}$, and the average temperature of the inner ring was $35^{\circ} \mathrm{C}$. Both of them are in the normal range.

Table 4. The temperature change of the tested bearing in 24 hours.

\begin{tabular}{|c|c|c|c|c|c|c|c|c|c|c|c|c|c|}
\hline Temperature $\left({ }^{\circ} \mathrm{C}\right)$ & $\mathbf{O} \mathbf{h}$ & $2 \mathrm{~h}$ & $4 \mathrm{~h}$ & $6 \mathrm{~h}$ & $8 \mathrm{~h}$ & $10 \mathrm{~h}$ & $12 \mathrm{~h}$ & $14 \mathrm{~h}$ & $16 \mathrm{~h}$ & $18 \mathrm{~h}$ & $20 \mathrm{~h}$ & $22 \mathrm{~h}$ & $24 \mathrm{~h}$ \\
\hline Inner ring & 28.3 & 34.6 & 35.2 & 35.3 & 35.0 & 35.2 & 35.1 & 34.7 & 34.9 & 35.2 & 35.1 & 35.0 & 34.9 \\
\hline Outer ring & 28.3 & 29.6 & 29.9 & 29.2 & 29.0 & 28.5 & 28.9 & 29.3 & 29.1 & 28.6 & 29.5 & 29.6 & 29.3 \\
\hline
\end{tabular}

Compared with the current wind turbine bearing test-bed, the test-bed in this paper can measure the bearing with a maximum diameter of 5 meters. The test-bed can test the bearing continuously for 2-3 months, so as to realize the simulation test of wind turbine bearing in natural environment. The loading method of the test-bed is safer and more reliable than other loading methods of the same kind of test-bed, and can realize automatic installation and testing.

\section{Conclusions}

Aiming at the lack of detection equipment for the main bearings of large wind turbines, this paper designs a real-time detection test bed based on the force status of the main bearings under actual working conditions. The loading experiment is carried out on the main bearing and the dynamic characteristics of the main bearing are obtained. The main conclusions are as follows.

(1) Using the analysis method of the spatial force system, the center load of the wind wheel hub is converted to the reference plane of the test bearing. Then the test bearing force system is converted to the axial and radial hydraulic cylinder load of the test bench, and a mathematical model of force system conversion is established. This force system conversion method realizes the simulation of the actual working condition of the bearing. The loading effect of the hydraulic cylinder of the test bench is equivalent to the force of the fan hub on the main bearing.

(2) Under the load conditions of constant torque, increasing torque and reducing torque, the axial displacement and radial displacement of the main bearing did not exceed 5 $\mathrm{mm}$ on the test bench, and showed periodic changes with rotation. In the steady state, the temperature change is in a steady state, and the temperature difference between the inner ring and the outer ring is not large. These are in line with the test standards that meet the main bearings of large wind turbines. The force loading method of the bearing test bench designed in this paper (working with the rotation of the motor and the loading of 8 hydraulic cylinders) provides a new design idea for the bearing inspection equipment.

The loading model proposed in this paper is based on main object and does not consider the deformation of the object in contact with the bearing (such as the loading component in Figure 8). Therefore, in future work, the material properties of the object in contact with the bearing can be analyzed and the deformation of the contact object can be considered, which makes the bearing test results more accurate.

\section{References}

[1] E. M. Farahani, N. Hosseinzadeh, and M. Ektesabi, "Comparison of fault-ride-through capability of dual and single-rotor wind turbines," Renewable Energy, vol. 48, pp. 473-481, 2012. 
[2] R. J. Bessa, C. Mohlen, V. Fundel et al., "Towards Improved Understanding of the Applicability of Uncertainty Forecasts in the Electric Power Industry," Energies, vol. 10, no. 9, Article ID 1402, 2017.

[3] L. M. Miller and D. W. Keith, "Climatic Impacts of Wind Power," Joule, vol. 2, no. 12, pp. 2618-2632, 2018.

[4] P. Gauglitz, S. Schicketanz, and C. Pape, "Nature conservation as a driver in wind energy scenarios," Energy Sustainability and Society, vol. 9, no. 1, Article ID 47, 2019.

[5] P. Pinson, C. Chevallier, and G. N. Kariniotakis, "Trading wind generation from short-term Probabilistic forecasts of wind power," IEEE Transactions on Power Systems, vol. 22, no. 3, pp. 1148-1156, 2007.

[6] D. Parks, "Promises and Techno-Politics: Renewable Energy and Malmo's Vision of a Climate-Smart City," Science as Culture, vol. 29, no. 3, pp. 388-409, 2019.

[7] B. Mantravadi, D. Unnikrishnan, K. Sriram et al., "Effect of solidity and airfoil on the performance of vertical axis wind turbine under fluctuating wind conditions," International Journal of Green Energy, vol. 16, no. 14, pp. 1329-1342, 2019.

[8] M. Graefe, C. Bert, and S. Winter, "Prestressed CLT wind-turbine towers," Bautechnik, vol. 94, no. 11, pp. 804-811, 2017.

[9] P. Marti-Puig, A. Blanco, J. J. Cardenas, J. Cusido, and J. Sole-Casals, "Effects of the pre-processing algorithms in fault diagnosis of wind turbines," Environmental Modelling \& Software, vol. 110, pp. 119-128, 2018.

[10] S. M. Banitaba, R. M. Ahari, and M. Karbasian, "Reliability model and sensitivity analysis for wind turbine with failure types based on non-identical correlated components," Energy Sources Part a-Recovery Utilization and Environmental Effects, 2019.

[11] H. Ren, W. Liu, M. Shan, and X. Wang, "A new wind turbine health condition monitoring method based on VMD-MPE and feature-based transfer learning," Measurement, vol. 148, Article ID 106906, 2019.

[12] P. K. Ray, B. K. Panigrahi, P. K. Rout, et al., "Detection of Islanding and Fault Disturbances in Microgrid using Wavelet Packet Transform," IETE Journal of Research, vol. 65, no. 6, pp. 796-809, 2019.

[13] E. Hart, A. Turnbull, J. Feuchtwang et al., "Wind turbine main-bearing loading and wind field characteristics," Wind Energy, vol. 22, no. 11, pp. 1534-1547, 2019.

[14] J. S. Nam, Y. J. Park, and H. S. Chang, "Dynamic life prediction of pitch and yaw bearings for wind turbine," Journal of Mechanical Science and Technology, vol. 30, no. 1, pp. 249-256, 2016.

[15] S. Zupan, R. Kunc, and I. Prebil, "Experimental determination of damage to bearing raceways in rolling rotational connections," Experimental Techniques, vol. 30, no. 2, pp. 31-36, 2006.

[16] J. F. Zhang, "Design and Analysis of Structure and Hydraulic System of Wind Power Main Bearing Testing Machine," Master, Dalian University of Technology, Dalian, China, 2019.

[17] Z. Chaib, A. Daidié, and D. Leray, "Screw behavior in large diameter slewing bearing assemblies: numerical and experimental analyses," International Journal on Interactive Design and Manufacturing, vol. 1, no. 1, pp. 21-31, 2007.

[18] A. Kusiak and A. Verma, "Analyzing bearing faults in wind turbines: A data-mining approach," Renewable Energy, vol. 48, pp. 110-116, 2012.

[19] T. Barszcz and N. Sawalhi, "Fault Detection Enhancement in Rolling Element Bearings Using the Minimum Entropy Deconvolution," Archives of Acoustics, vol. 37, no. 2, pp. 131-141, 2012.

[20] J. Zhu, N. Chen, and C. Shen, "A new data-driven transferable remaining useful life prediction approach for bearing under different working conditions," Mechanical Systems and Signal Processing, vol. 139, Article ID 106602, 2020.

[21] L. Cao, Z. Qian, H. Zareipour et al., "Prediction of Remaining Useful Life of Wind Turbine Bearings under Non-Stationary Operating Conditions," Energies, vol. 11, no. 12, Article ID 3318,2018

[22] A. J. Hu, L. Xiang, and L. J. Zhu, "An engineering condition indicator for condition monitoring of wind turbine bearings," Wind Energy, vol. 23, no. 2, pp. 207-219, 2020.

[23] J. Y. Zheng, J. C. Ji, S. Yin, and V. C. Tong, "The Load Distribution of the Main Shaft Bearing Considering Combined Load and Misalignment in a Floating Direct-Drive Wind Turbine," In: 2018 3rd International Conference on Power and Renewable Energy, vol. 64, Article ID 07009, 2018.

[24] J. Y. Zheng, J. C. Ji, S. Yin, and V. C. Tong, "Internal loads and contact pressure distributions on the main shaft bearing in a modern gearless wind turbine," Tribology International, vol. 141, Article ID 105960, 2020.

[25] E. Hart, "Developing a systematic approach to the analysis of time-varying main bearing loads for wind turbines," Wind Energy, vol. 23, no. 12, pp. 2150-2165, 2020.

[26] T. Rauert, J. Herrmann, P. Dalhoff, and M. Sander, "Fretting fatigue induced surface cracks under shrink fitted main bearings in wind turbine rotor shafts," In: 21st European Conference on Fracture, vol. 2, pp. 3601-3609, 2016.

[27] E. Hart, A. Turnbull, D. McMillan et al., "Investigation of the relationship between main-bearing loads and wind field characteristics," In: Windeurope Conference \& Exhibition 2017, vol. 926, Article ID 012010, 2017.

[28] C. J. Lin, W. L. Chu, C. C. Wang, C. C. Chen, and I. T. Chen, "Diagnosis of ball-bearing faults using support vector machine based on the artificial fish-swarm algorithm," Journal of Low Frequency Noise Vibration and Active Control, vol. 39, no. 4, pp. 954-967, 2020.

[29] X. L. Wang, X. L. Yan, and Y. L. He, "Weak Fault Feature Extraction and Enhancement of Wind Turbine Bearing Based on OCYCBD and SVDD," Applied Sciences-Basel, vol. 9, no. 18, Article ID 3706, 2019.

[30] J. Ben Ali, L. Saidi, S. Harrath, E. Bechhoefer, and M. Benbouzid, "Online automatic diagnosis of wind turbine bearings progressive degradations under real experimental conditions based on unsupervised machine learning," Applied Acoustics, vol. 132, pp. 167-181, 2018. 